\title{
Penile Cancer in Liberia: A Case Report and Review of the Literature
}

\author{
Edet Ikpi'1,2*, Solomane Konneh1, Bashir Yunusa1,2, Ansumana Camara1, Alberta Clark1, \\ Sean Subah1, David Alele1,2, Monica Sroden ${ }^{3}$ \\ ${ }^{1}$ Urology Division, Department of Surgery, JFK Memorial Hospital, Monrovia, Republic of Liberia \\ ${ }^{2}$ Department of Surgery, Icahn School of Medicine, Mount Sinai, New York, USA \\ ${ }^{3}$ Department of Pathology, Waterbury Hospital, Waterbury, USA \\ Email: *eeikpi@yahoo.com
}

How to cite this paper: Ikpi, E., Konneh, S., Yunusa, B., Camara, A., Clark, A., Subah, S., Alele, D. and Sroden, M. (2018) Penile Cancer in Liberia: A Case Report and Review of the Literature. Health, 10, 1132-1139.

https://doi.org/10.4236/health.2018.108086

Received: August 1, 2018

Accepted: August 27, 2018

Published: August 30, 2018

Copyright (c) 2018 by authors and Scientific Research Publishing Inc. This work is licensed under the Creative Commons Attribution International License (CC BY 4.0).

http://creativecommons.org/licenses/by/4.0/

(c) (i) Open Access

\begin{abstract}
Background: Penile cancer is uncommon in Liberia with no record of its occurrence so far in the literature. Its occurrence worldwide is significantly affected by cultural or religious practices like childhood circumcision. Smoking, poor penile hygiene and inflammatory processes in the presence of smegma increase the risk of its occurrence. Objective: To review the first case of penile cancer treated in Liberia. Materials and Method: Case report. Case Presentation/Report: Our index patient is a 65-year old man referred from a peripheral centre in acute urinary retention. He also presented with a year history of progressively expanding ulcerative penile lesion affecting the glans and penile shaft. Local examination of the genitalia revealed an ulcerated lesion extending from the glans up to the mid shaft of the penis. The peno-bulbar urethra was free of induration. The external urethral meatus was infiltrated by the lesion. The scrotum and testes were normal and digital rectal examination revealed a moderately enlarged benign prostate. Bilateral inguinal lymph node enlargement was elicited. A diagnosis of advanced penile cancer with benign prostatic hyperplasia was made. The patient had partial penectomy, reconstruction of new external urethral meatus and inguinal lymphadenectomy. The specimen was histologically confirmed to be Squamous cell Carcinoma of the penis; the resection margins and lymph nodes biopsied were found to be adequate and tumor free respectively. Patient's post operative recovery was uneventful and he was discharged after a week. His follow up status after 6 months has remained satisfactory. Conclusion: Though rare, penile cancer does occur in Liberia and specialist staff with capacity for diagnosing and surgical intervention remains critical to patients' outcome. Early intervention improves the chances of better outcome; counseling is critical to prevent treated patient lapsing into depression.
\end{abstract}




\section{Keywords}

Carcinoma, Penis, Penectomy

\section{Introduction}

Penile cancer is believed to be uncommon in Liberia as a result of the absence of any previous report of its occurrence in the literature; there is also a lack of any case documented until now in hospital records after the Liberian civil war. This index case is therefore, the first documented case of penile cancer in Liberia.

The prevalence of penile cancer worldwide differs from region to region. Its occurrence is modulated by the socio-economic status of the people as well as their religious practices. It is rare in countries where neonatal male circumcision is practiced [1]. This may explain the relative rarity of this condition in Liberia where circumcision is commonly practiced amongst all tribes.

Penile cancer is a psychologically traumatizing disease condition which commonly affects the epithelium of the glans penis and spreads proximally along the phallus and through the lymphatics predominantly, to the inguinal lymph nodes. The common histological type is Squamous cell carcinoma associated with strain 16 and 18 high risk Human Papilloma Virus [2].

There are several benign lesions like syphilitic chancre, chancroid and lichen planus amongst others which can mimic penile cancer and these need to be differentiated from malignant and pre-malignant penile lesions [3].

In low resource settings, the importance of a good clinical history and thorough physical examination cannot be overemphasized. Collaboration with centers which have capacity for histological confirmation is in imperative for grading and tumour typing.

The objective of this paper is to draw attention to the occurrence of this condition in Liberia as a base line case and thereby, increase the sense of suspicion of the occurrence of penile cancer amongst medical practitioners in the West African Sub-region.

\section{Case Report}

A 65-year-old man was seen in the emergency room of JFK Memorial Hospital, Monrovia (Liberia's only Teaching Hospital), with complaints of an initially reddish, circumscribed painless penile skin lesion which progressively expanded, resulting eventually in a painful penile ulcer that easily bled on contact. The ulcerated lesion extended from the glans penis to the mid shaft of the penis and was associated with a complete destruction of the glans penis (Figure 1). There was also involvement of the external urethral meatus over the course of one year.

The patient's symptoms also included progressive obstructive lower urinary tract symptoms culminating in acute urinary retention which prompted the 


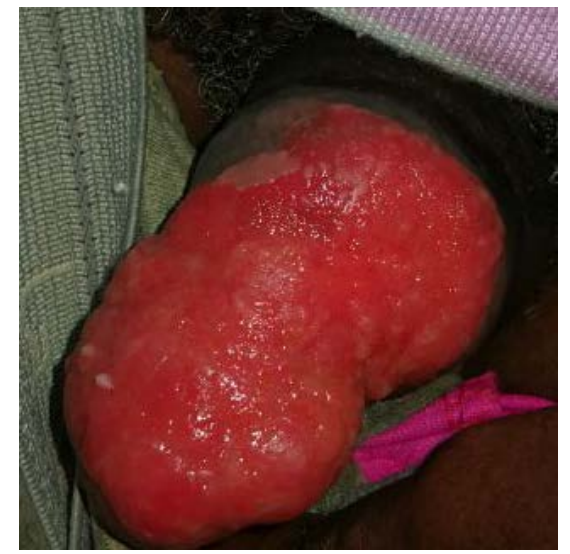

Figure 1. Carcinoma of the penis with the destruction of the glands penis.

patient to seek medical treatment. Attempts at urethral catherization in the peripheral hospital were unsuccessful warranting his referral to JFK Memorial hospital for emergency supra-pubic catheterization.

Patient was circumcised in infancy and although married, he admitted having unprotected sex with multiple partners. He denied any history of visible sexually transmitted infection (STI), weight loss or anorexia. He is not a known diabetic or hypertensive but confirmed consumption of generous amounts of alcohol and several packets of different brands of cigarettes daily for over ten years.

Physical examination revealed an elderly, moderately nourished, unkempt male in painful distress and disorientated in time, place and person. He was afebrile with an 18 week size suprapubic bladder distension. There were no other significant abdominal findings except for bilateral discrete enlarged inguinal lymph nodes with a larger node found on the left.

Local examination of the genitalia revealed an ulcerated lesion of the penis involving all of the glans penis and extending beyond the mid shaft of the penis. The external urethral meatus was occluded but no induration was palpable along the length of the peno-bulbar urethra. The scrotum and testes were normal and digital rectal examination revealed a moderately enlarged benign prostate.

A diagnosis of advanced penile cancer with benign prostatic hyperplasia was made. Routine investigations of his prostate confirmed benign prostatic hyperplasia and a fine needle aspiration cytology of the penile lesion raised suspicion of Squamous cell carcinoma of the penis. Image capturing capability of the fine needle cytology are unavailable in our extremely low resource setting. The patient had partial penectomy, reconstruction of new urethral meatus over a urethral catheter and inguinal lymphadenectomy (Figure 2). The specimens were sent for histopathology at Waterbury Hospital, CT. and the lesion was confirmed to be Squamous cell Carcinoma of the penis; the resection margins and lymph nodes biopsied were adequate and tumor free.

Patients post operative recovery was uneventful and he was counseled and discharged after a week. His follow up status after 6 months has remained satisfactory. 


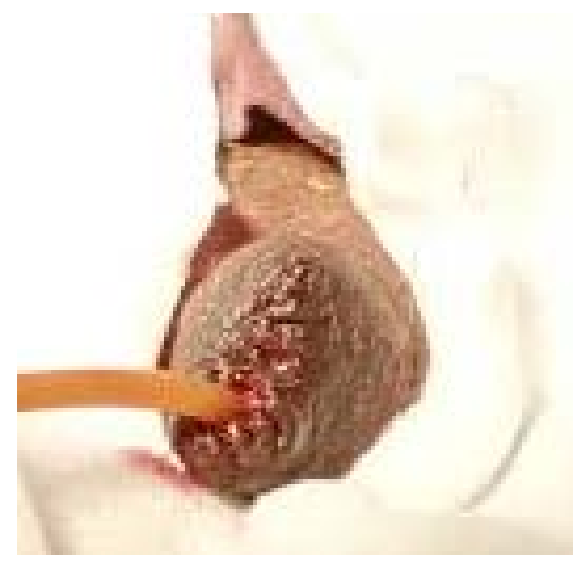

Figure 2. Penectomy and reconstruction of new urethral meatus.

\section{Discussion}

Penile carcinoma is an uncommon condition, accounting for less than $1 \%$ of all male cancer [4]. It is most commonly seen in developing countries. Brazil has the highest incidence in the world with a rate of 2.9 to 6.8 per 100,000. In Maranhão, a poorly developed region in Brazil, penile cancer was reported in 53\% of males [5]. The highest prevalence of the disease is found in uncircumcised, low-income Caucasian men. The lowest rate of penile cancer is found in Israel [6]. It represents about $10 \%$ of cancers in South America and some African countries [7].

On the African continent, Uganda is reported to have the highest prevalence rate of 3 - 4 per 100,000 over the past several decades. Zimbabwe and Swaziland have reported rates of $(1.6 / 100,000)$ and $(3.2 / 100,000)$ respectively [8].

In Nigeria, seven (7) cases of carcinoma of the penis accounting for $1.9 \%$ of malignant lesions of the male genitalia were reported in Lagos over a period of 20 years [9], while six (6) cases were seen in Kano over 18 year period [10]. The lowest rates $(0.1 / 100,000)$ have been found in Israeli Jews and this may be attributed to the practice of neonatal circumcision. It is also seldom seen among Muslims, who practice routine circumcision from neonatal age through the ages of 3 - 13 [11].

Our patient is aged 65 years, falling within the age range described in some studies which have found penile cancers among men aged 50 - 75 yrs with a mean of 59.70 years [11].

Infection with Human Papilloma virus (HPV) is an established etiological agent for the development of Penile Cancer (PC) in about 35\% - 82\% of patients. The presence of papular skin lesions on the glans and proximal shaft of his penis for many years prior to the onset of ulceration in our patient may indicate an etiological relationship with HPV [4] [12].

Phimosis, in association with poor hygiene, accumulation of smegma and chronic inflammation increases the risk of developing penile cancer and has been linked with as many as $90 \%$ of cases in some studies [13] [14]. 
Our patient admitted smoking several packets of different brands of cigarette per day for more than ten years. Strong association between cigarette smoking and penile cancer has long been established. Tobacco exerts its action directly after systemic absorption, through its metabolites, or through a tobacco-specific nitrosamine 4-(methylnitrosamiol-1-(3-pyridyl)-1butanone (NNK) which is usually found in the urine of smokers. The risk of developing penile cancer increases further when more than one type of tobacco is consumed [15] [16].

The classical clinical characteristics of penile cancer consist of an ulcerated lump that may be itchy, painful, and associated with contact bleeding. The ulcer is often further complicated by a secondary infection [17], as presented by our patient. In some series the cancer shows a striking predilection for the glans penis $(50 \%)$, followed by the glans and prepuce (33.3\%), and the shaft (16.7\%) [18]. Ourpatient presented with a completely deformed and ulcerated glans penis extending up to the mid shaft of the penis. Involvement of the urethra resulted in urinary flow obstruction and consequent acute urinary retention that warranted suprapubic catherization.

Inguinal lymph node involvement is associated with advance disease and patients generally have a significantly negative quality of life where the disease is complicated by the presence of obstructive lower urinary symptoms as documented in our patient [19] [20].

The confirmatory diagnosis of this condition is tissue histology, a service that is currently unavailable in Liberia. The opportunity to have our specimen processed and read in Waterbury Hospital, CTUSA confirmed our suspicion of penile squamous cell carcinoma as shown in Figure 3 and Figure 4. The patients' long term disease recurrence free rate may significantly be improved by

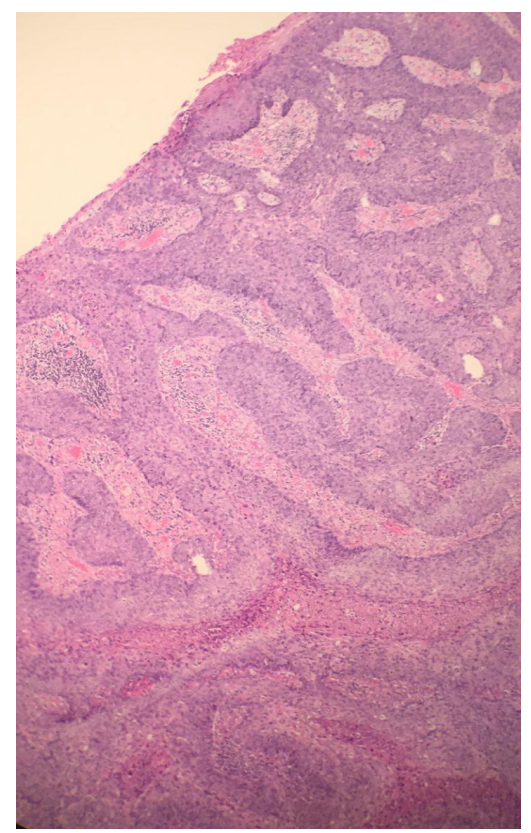

Figure 3. A highly cellular smear with hyperchromatic cells exhibiting anisocytosis with nuclear molding, cytoplasmic ringing and abundant squams in the cytoplasm. $\times 40$. 


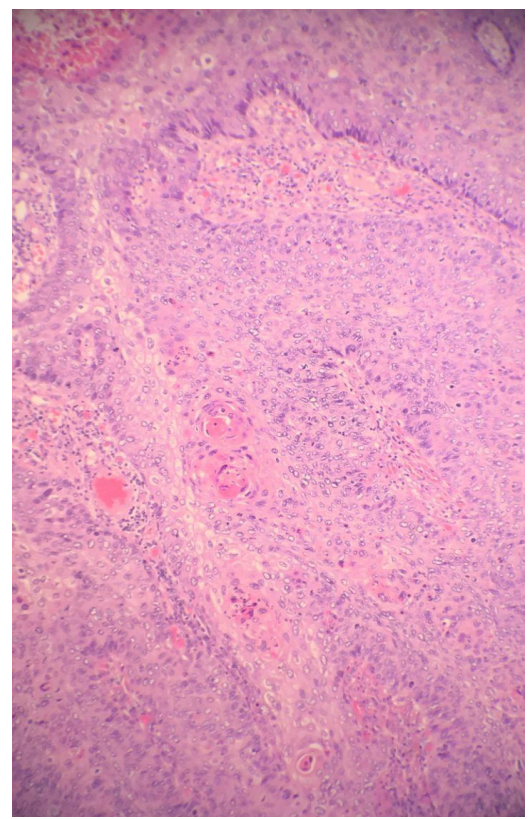

Figure 4. $\mathrm{H}$ and $\mathrm{E}$ section showing atypical squamous cells with nuclear atypia and pleomorphism that extend from the surface down to the basement membrane. There are prominent intercellular bridges and keratin pearls.

the wide tumor free excision margins and the confirmation of negative inguinal lymph node. Liberia does not yet have facilities for radiotherapy and even chemotherapeutic medications are extremely difficult to come by.

It should be noted that until recently, Liberia had no urologist in service. This may account for the low documentation of urological cases in the literature. The deployment of medical specialists to Liberia by The Icahn School of Medicine at Mount Sinai, New York, under the World Banks' Health workforce Projectis certainly going to increase the understanding, appreciation and outcomes of medical conditions in Liberia.

\section{Conclusion}

This is the first reported case of penile cancer, making it a rare disease in Liberia. It is associated with significant psychological and post-treatment adverse effects. Documented risk factors for penile cancer are phimosis associated with poor personal hygiene and HPV infection resulting usually from sexual promiscuity associated with unprotected sexual intercourse and other STIs. Poor socio-economic status may render one vulnerable to developing penile cancer. The most common histological patterns are squamous cell carcinoma. Public education, improvement in socio-economy, personal hygiene and possibly routine circumcision may reduce the rates in high-risk groups.

\section{Acknowledgements}

1) Icahn School of Medicine, Mount Sinai, New York.

2) Dr. David Knight, Waterbury Hospital, Connecticut. 
3) Liberian College of Physicians and Surgeons.

\section{Conflicts of Interest}

Nil.

\section{Patient Consent}

Obtained for publication.

\section{References}

[1] Christodoulidou, M., Sahdev, V., Houssein, S. and Muneer, A. (2015) Epidemiology of Penile Cancer. Current Problems in Cancer, 39, 126-136. https://doi.org/10.1016/j.currproblcancer.2015.03.010

[2] Barnholtz-sloan, J.S., Maldonado, J.L., Pow-Sang, J., Giuliano, A.R. and Guiliano, A.R. (2007) Incidence Trends in Primary Malignant Penile Cancer. Urologic Oncology, 25, 361-367. https://doi.org/10.1016/j.urolonc.2006.08.029

[3] Spiess, P.E., Horenblas, S., Pagliaro, L.C., Biagioli, M.C., Crook, J., Clark, P.E., et al. (2013) Current Concepts in Penile Cancer. Journal of the National Comprehensive Cancer Network, 11, 617-624. https://doi.org/10.6004/jnccn.2013.0076

[4] Wilson, C.N. and Sathiyasusuman, A. (2015) Associated Risk Factors of STIs and Multiple Sexual Relationships among Youths in Malawi. PLoS ONE, 10, 134286.

[5] Favorito, L.A., Nardi, A.C., Ronalsa, M., Zequi, S.C., Sampaio, F.J. and Glina, S. (2008) Epidemiologic Study on Penile Cancer in Brazil. International Brazilian Journal of Urology, 34, 587-591. https://doi.org/10.1590/S1677-55382008000500007

[6] Morrison, B.F. (2014) Risk Factors and Prevalence of Penile Cancer. West Indian Medical Journal, 63, 559-560.

[7] Parkin, D.M., Ferlay, J., Hamdi-Cherif, M., Sitas, F., Thomas, J.O., Wabinga, H., et al. (2003) Cancer Incidence in Africa. International Agency for Research on Cancer, Lyon.

[8] Parkin, D.M. (2002) Cancer Incidence in Five Continents. International Agency for Research on Cancer, Lyon.

[9] Ajekigbe, A.T., Anunobi, C.C., Tijani, K.H., Banjo, A.A. and Nweke, I.G. (2011) Carcinoma of the Penis: Experience from the Lagos University Teaching Hospital Lagos, Nigeria. Nigerian Quarterly Journal of Hospital Medicine, 21, 25-28.

[10] Abubakar, A., Sule, A. and Haruna, M.S. (2017) Pattern of Penile Cancerin Kano, Nigeria. Journal of Basic and Clinical Sciences,14, 15-17.

[11] Guimarães, G.C., Rocha, R.M., Zequi, S.C., Cunha, I.W. and Soares, F.A. (2011) Penile Cancer: Epidemiology and Treatment. Current Oncology Reports, 13, 231-239. https://doi.org/10.1007/s11912-011-0163-2

[12] Shabbir, M., Barod, R., Hegarty, P.K. and Minhas, S. (2013) Primary Prevention and Vaccination for Penile Cancer. Therapeutic Advances in Urology, 5, 161-169. https://doi.org/10.1177/1756287212465456

[13] Gerber, G. (1994) Carcinoma in Situ of the Penis. Journal of Urology, 151, 829-833. https://doi.org/10.1016/S0022-5347(17)35099-1

[14] Wiener, J.S. and Walther, P.J. (1995) The Association of Oncogenic Human Papillomaviruses with Urologicmalignancy. Surgical Oncology Clinics of North America, 4, 257-276. https://doi.org/10.1016/S1055-3207(18)30452-6 
[15] Harish, K. and Ravi, R. (1995) The Role of Tobacco in Penile Carcinoma. British Journal of Urology, 75, 375-377. https://doi.org/10.1111/j.1464-410X.1995.tb07352.x

[16] Hect, S.S., Akerkar, S. and Carmnella, S.G. (1993) Metabolites of Tobacco Specific Nitrosamine 4(methylnitrosamino)-1-(3-pyridyl)-1-Butanone in Smokers Urine. Proceedings of the American Association for Cancer Research, 34, 909.

[17] Pow-Sang, M.R., Benavente, V., Pow-Sang, J.E., Morante, C., Meza, L., Baker, M., et al. (2002) Cancer of the Penis. Cancer Control, 9, 305-314. https://doi.org/10.1177/107327480200900405

[18] Burgers, J.K., Badalament, R.A. and Drago, J.R. (1992) Penile Cancer. Clinical Presentation, Diagnosis, and Staging. Urologic Clinics of North America, 19, 247-256.

[19] Derakhshani, P., Neubauer, S., Braun, M., Bargmann, H., Heidenreich, A. and Engelmann, U. (1999) Results of 10 Year Follow-Up in Patients with Squamous Cell Carcinoma of the Penis. Urologia Internationalis, 62, 238-244. https://doi.org/10.1159/000030405

[20] Cubilla, A.L., Reuter, V., Velazquez, E., Piris, A., Saito, S. and Young, R.H. (2001) Histologic Classification of Penile Carcinoma and Its Relation to Outcome in $61 \mathrm{~Pa}-$ tients with Primary Resection. International Journal of Surgical Pathology, 9, 111-120. https://doi.org/10.1177/106689690100900204 